\title{
Understanding the Influence of Time Pressure and Social Ties on Public Sector Supplier Selection Decisions: A Polychronic Context Explanation
}

\author{
Eyo Emmanuel Essien ${ }^{1}$, Christian Amadi ${ }^{2}$, \& Rajunor Bassey Anani ${ }^{1}$ \\ ${ }^{1}$ Dr., Department of Marketing, University of Calabar, Calabar, Nigeria. \\ ${ }^{2}$ Dr., Department of Administration, Federal University Wukari, Taraba State, Nigeria. \\ Correspondence: Dr. Eyo E. Essien, Department of Marketing, Faculty of Management Sciences, University of \\ Calabar, P. M. B. 1115, Calabar, Cross River State, Nigeria.
}

Received: January 11, 2019

Accepted: February 1, 2019

Online Published: February 11, 2019

doi:10.5539/ibr.v12n3p79

URL: https://doi.org/10.5539/ibr.v12n3p79

\begin{abstract}
This study investigated the influence of time pressure perception and social ties on the supplier selection decisions and performance of public firms in a typically polychronic cultural setting. Using a structured questionnaire, data were collected from 342 senior level personnel in 40 public sector organizations in Nigeria and analyzed using structural equation modeling (SEM) techniques. The study's results indicate that while time pressure has no significant influence on supplier selection decision, its impact on performance is significant and negative. The results also show that social ties are significant positive predictors of supplier selection decisions, but their relationship with performance is insignificant. However, the study also found that supplier selection decisions positively influence performance, and supplier selection decisions positively mediates the relationship between social ties and perceived performance. Based on the study's findings and conclusions, important implications for practice and suggestions for further research are discussed.
\end{abstract}

Keywords: time pressure, social ties, supplier selection decisions, perceived performance, public sector, Nigeria

\section{Introduction}

Over the years, the number of studies in business-to-business marketing literature using sociological and psychological concepts to explain organizational choice behavior have been rising. This trend is due partly to the inadequacies of 'rational' economic theories in explaining the 'irrational' buying behavior observed in many empirical studies, and partly because of the robustness of social and psychological variables in explaining choice behavior (Hadjikhani \& LaPlaca, 2013; Ho, Lim, \& Camerer, 2006; Iyer, Xiao, Sharma, \& Nicholson, 2015). Collectively, these studies have contributed to our understanding of some of the salient behavioral and non-economic determinants of organizational buying process and outcomes. Some of the determinants of organizational buying behavior that have received attention in recent marketing literature include time pressure perception (e.g., Garrido-Samaniego \& Gutiérrez-Cillán, 2004) and the social ties of organizational decision-makers (e.g., Essien, Konstantopoulou, Konstopoulos, \& Lodorfos, 2018; Peng \& Luo, 2000; Sheng, Zhou, \& $\mathrm{Li}, 2011)$. However, the findings on the influence of these variables with respect to organizational decision processes and outcomes differ significantly. For example, empirical studies have shown that depending on internal (individual cognitive) and external (socio-cultural environmental) factors, the effect of time pressure perception on organizational processes may be positive, non-existent, or negative (Chong, Eerde, Chai, \& Rutte, 2011). Similarly, studies associating social ties of organizational actors with organizational decisions behavior have demonstrated that the influence of social ties may either be positive (in terms of guaranteeing survival and performance) or negative (in terms of constituting a liability), depending on context-specific environmental factors such as socio-cultural values and level of economic development (Faccio, 2010; Sheng et al., 2011).

Given these inconsistent findings, there is a need to conduct more contextualized studies to enhance the generalizability of results. Although there has been some discussion on the underlying reasons for the observed mixed finding on the roles of time pressure and social ties in organizational processes, only a handful of studies have expressly explored the influence of these variables on organizational buying decisions in a typically polychronic cultural setting. Polychronic cultural orientation theory suggest that the relationship between time 
pressure perception and decision-making outcomes, for example, depends not on the level of pressure but on the region of the world as well as the economic value attached to time (Capdeferro, Romero, \& Barberà, 2014; Kaufman-Scarborough \& Lindquist, 1999; Nonis, Teng, \& Ford, 2005; Xu-Priour, Cliquet, \& Palmer, 2017). Furthermore, the theory suggests that people in polychronic cultures value interpersonal relationships with family members, friends, business associates, etc.; that attitude towards time is hinged much more on tradition, religion, personal relationships, than keeping to planned schedules or accomplishing a given task (Benabou, 1999; Bluedorn, Kaufman, \& Lane, 1992). To the best of our knowledge, no previous study has examined the relationship among time pressure perception, social ties and organizational outcomes (i.e., supplier selection decisions and performance), even when the literature appears to suggest some linkages. Therefore, the main objective of this study is to investigate the association among time pressure perception, social ties, supplier selection decisions, and perceived performance. The present study contributes to the business-to-business marketing and public procurement literature by testing a model that explores the relationship among these constructs in a typically polychromic setting like Nigeria.

The contents of this paper are arranged as follows. Following the foregoing introduction, a clarification of the constructs' domain is done by a review of the theory of polychronicity. The development of the proposed hypothesized relationships among the constructs is discussed, following the review. A description of the research methodology, including participants, construct measures, and measurement reliability and validity, is given after the section on hypotheses development. The results of data analysis and the implications for policy are presented and discussed. The paper concludes by highlighting the main limitations of the study, as well as making suggestions for further study.

\section{Theoretical Background.}

The concept of polychronicity was first developed by Hall (1959) to describe a preference for undertaking multiple activities within a given time block (Bluedorn et al., 1992). Subsequent studies by various researchers from different backgrounds have resulted in different views of the concept of polichromicity, and the subsequent evolution of Hall's (1959) construct into, at least, three significant conceptual spheres: polychronicity related to time-use, polychronicity related to time tangibility, and policronicity related to a people's culture (Arndt, Arnold, \& Landry, 2006; Ayoun \& Moreo, 2009; Benabou, 1999; Kaufman-Scarborough \& Lindquist, 1999). This paper is interested in the cultural strand of the theory of polychronicity. In order to frame the scope of our study however, we briefly discuss the other views of the phenomenon.

The literature categorize Polychronicity related to time-use pattern into two (Arndt et al., 2006; Bluedorn, Kalliath, Strube, \& Martin, 1999): (1) multi-tasking (or simultaneous-tasking); and (2) task-switching. Multi-tasking has to do with the tendency to engage in two or more task at the same time (Bluedorn et al., 1992). This tendency is common to most people. It is very possible to be talking on the phone and walking, for example, because the senses or body parts required to carry out these tasks are different. Studies generally seem to suggest that routine tasks requiring no differential perceptual inputs are more amenable to simultaneous performance than, say, typing on a computer and watching a game of football on television at the same time (Arndt et al., 2006). Where the tendency is for individuals to move back and forth between tasks within a given time block, such preference or behavior is referred to as task-switching (Bluedorn et al., 1999; Capdeferro et al., 2014). People who prefer to complete one task at a time before moving to another are termed monochronics, while polychronics are individuals who like to juggle or switch between multiple activities within a given time block (Arndt et al., 2006; Kaufman-Scarborough \& Lindquist, 1999). Although we have discussed polychronicity related to time-use as two distinct concepts, there are literature which tend to blur this distinction thereby treating the concepts as one and the same (e.g., see the literature review by Capdeferro et al., 2014).

Time tangibility as an aspect of polychronicity theory explores individuals' view of time as a resource which needs to be planned and accounted for (Chen, Xu, \& Zheng, 2015; Lindquist \& Kaufman-Scarborough, 2007). This view of polychronicity argues that time is a commodity that can be spent, clocked, valued, redeemed, lost, and planned (Arndt et al., 2006; Capdeferro et al., 2014; Palmer \& Schoorman, 1999). Again, this theory makes a distinction between monochrons- individuals who structure their activities and events to fit strictly within a specified time frame, and polychrons-individuals who believe that time cannot be controlled; they believe that time is defined by activities/events within a given period. (Arndt et al., 2006; Lindquist \& Kaufman-Scarborough, 2007). It must be said at this point that this aspect of the theory captures the temporal nature of individuals that explains the manner people structure their time in relation to the tasks or events that require their attention (Lee \& Sawyer, 2010).

Polychronism as a cultural phenomenon (which is the focus of this paper) also formed part of Hall's (1959) 
original conceptualization of the phenomenon. By way of further explanation, Bluedorn et al. (1999) defined polychronic cultures as people who prefer to engage in two or more tasks or activities simultaneously whilst still believing that their preference is the best way of doing things. This view of polychronicity is important for, at least two reasons: (1) it taps into the values (preference) and beliefs of a collective (society) - ingredients that are essential to the definition of the cultural peculiarity of a given society (Bluedorn et al., 1999; Capdeferro et al., 2014); and (2) it has also been empirically shown to significantly correlate with national cultures (Ayoun \& Moreo, 2009; Hall, 1983; Rees-Caldwell \& Pinnington, 2013; Xu-Priour, Truong, \& Klink, 2014), as well as determining a broad range of organizational behavior and outcomes (Arndt et al., 2006; Xu-Priour et al., 2017). The literature on culture-oriented studies of polychronicity largely suggest that polychronic cultures, among other things, are less concerned with time pressure and deadlines, place more value on relationships and interpersonal relationships than accomplishing task or achieving objectives, are willing to change plans at short notice, do not mind interruptions or postponement, undertake multiple tasks/projects simultaneously and move from one project to another without much regards for end-dates, and consider time to be an intangible and uncontrollable phenomenon (Ayoun \& Moreo, 2009; Bluedorn et al., 1992; Hall, 1983; Kaufman-Scarborough \& Lindquist, 1999; Mohammed \& Nadkarni, 2014; Nonis et al., 2005). While it is largely confirmed that different countries or regions of the world can be described as being either polychronic or monochronic cultures (on the basis of their value systems), it is also possible, in polychronic societies, to find individuals who live and operate by monochronic values (Bluedorn et al., 1999).

The cultural perspective of the theory of polychronicity throws up some important elements that form the basis of this paper. First, regions of the world are characterized based on whether they are polychronic or monochronic cultures, and such characterizations have been applied to explain or predict their attitude and decision behavior (Ayoun \& Moreo, 2009; Kotabe \& Helsen, 2001; Van Everdingen \& Waarts, 2003; Xu-Priour, Cliquet, \& Fu, 2012). For example, Kotabe and Helsen (2001) used a ranking of 1 for 'very monochronic' and 20 for 'very polychronic' to scale a variety of countries based on their time orientation. They ranked Western European countries such as Germany, Sweden, France, U.S.A, and Canada on the upper rung of the ladder (i.e., very monochronic), while countries in Latin America, the Middle East and Africa are located on the lower rung of the ladder (i.e., very polychronic). This finding is supported by Xu-Priour et al. (2012) who found that the Japanese and Chinese tilt toward the polychronic side of the scale. Furthermore, this idea of culture-based time orientation has been used to determine consumer channel choice decision under time pressure in China (Xu-Priour et al., 2012), and to explain the variation in time pressure perception among consumers in various countries when adopting new product (Van Everdingen \& Waarts, 2003).

Second, the theory hints at the relative importance of time pressure perception and interpersonal relationships (social ties) in polychronic cultures. For instance, Zimbardo \& Boyd (2015) contend that people's perception of time is learned and shaped by their environment and experience, and this may influence their cognitive thought processes and choice behavior. It has also been demonstrated that time pressure perception (measured in terms of how much time is available or needed) is subjective and influenced by individual differences (at the individual level), and by socio-cultural value systems (at the society or aggregate level) (Capdeferro et al., 2014; García \& Ruiz, 2015; Hall, 1983; Lee \& Sawyer, 2010). More so, it is documented in the relevant literature that polychrons are not perturbed by the need to hurriedly complete a task or make a choice because they feel they can afford to delay (Arndt et al., 2006; Nonis et al., 2005; Xu-Priour et al., 2012). In the same vein, people in polychronic cultures are said to value interpersonal relationships with friend, family members and business associates to the detriment of keeping to schedules or accomplishing time-bound tasks (Benabou, 1999; Hall, 1983). For the managers and decision-makers in polychronic cultures, the bonds engendered by satisfying the needs of their social network is far more important than the arbitrariness and stricture of time, or the consequences of not acting or living by its dictates. Using the theoretical lenses provided by the culture-based postulations of polychronicity, the current study explores the effect of decision-maker's time pressure perception and social ties (interpersonal relationships) on supplier selection decisions and performance in a typically polychronic context like Nigeria.

\section{Conceptual Model and Hypotheses}

The model developed and tested in this study is presented in Figure 1. As an overview, this study proposes that time pressure perception and social ties of public sector organizational decision-makers will impact both supplier selection decisions and perceived performance in public sector firms. We also hypothesize that the choice of one supplier over another may have a consequential impact on the performance of the organization. Public sector supplier selection decisions entail the choice of suppliers/contractors from a short-list of pre-qualified vendors (based on pre-defined criteria) to be signed-on as providers of goods and services on behalf of public firms. For 
every public sector decision, there is a goal to be achieve (Akenroye, 2013), and these goals may range from qualitative (subjective) to quantitative considerations (Lindskog, Brege, \& Brehmer, 2010; Pestieau, 2009). Studies on polychronic behaviors based on national cultures and value systems indicate that polychrons are less likely to be bothered by conditions of time pressure during important decision situation, but will rather be concerned about solidifying their relationship with associates and key stakeholders (Bluedorn et al., 1999; Rees-Caldwell \& Pinnington, 2013; Van Everdingen \& Waarts, 2003). Our study contributes to the public sector marketing literature by proposing a series of relationships among time pressure perception, social ties of organizational members, supplier selection outcomes and performance in public sector organizations.

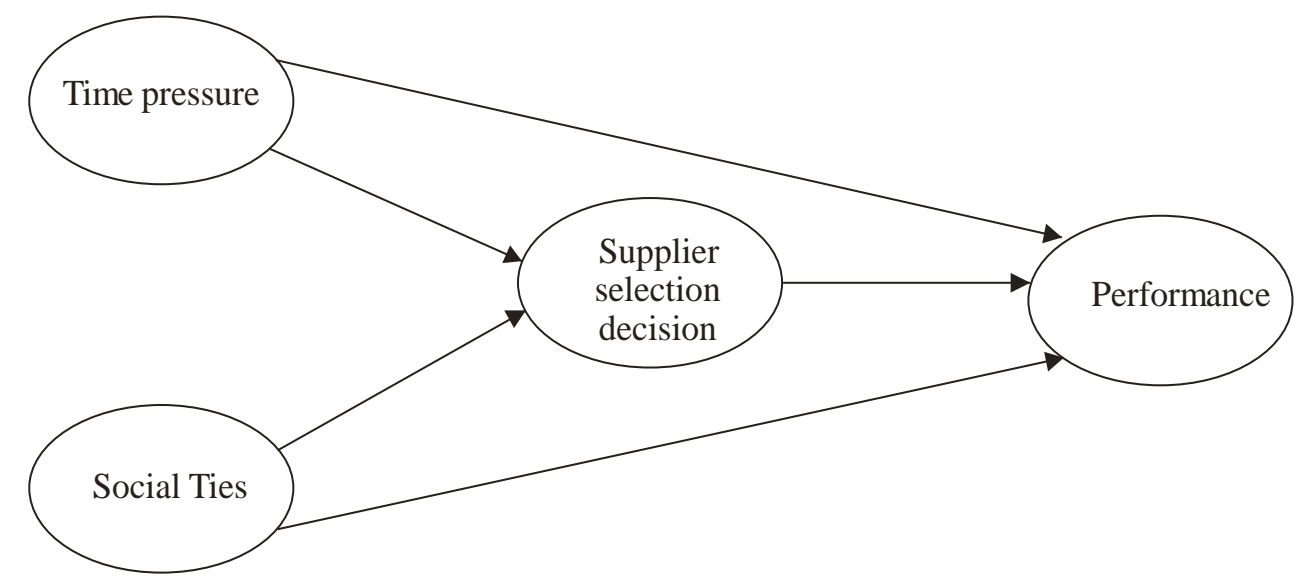

Figure 1. Conceptual model

\subsection{Time Pressure Perception}

Supplier selection decision in the public sector refers to the near-terminal stage in the procurement process where a decision is made to select one or a few contractors from a short-list of pre-qualified bidders (Lindskog et al., 2010). For public sector organizations, the selection of the 'right' contractor is important, not least for the timely completion of public works projects (Achua, 2011) and the achievement of the multi-faceted (and sometime conflicting) goals that often characterize public procurement exercises (Akenroye, 2013; Malloy \& Agarwal, 2010). For example, while it is important for public sector decision-makers to engage competent contractors who will deliver overall value-for-money (because the principle of due process and accountability demands it), it is not uncommon to find contractors who were awarded government contracts solely as compensation or 'pay-back' for their support for the incumbent government (Achua, 2011; Peng \& Luo, 2000). For the public sector decision maker therefore, the utility of selecting a supplier that meets both the subjective and objective goals of the decision situation at hand cannot be discounted.

Most public administrations operate within a statutorily prescribed life-span within which they must demonstrate to the public that their supplier decision choices (amongst several other important policy decisions) are in the best interest of the public. To this end, public organizations must focus (prioritize) and plan the resources - time, money, natural and human endowments - at their disposal to meet the expectation of the electorate. Given that public sector decision makers have a limited life-span after which they will need to be re-elected (re-appointed), time pressure/adequacy is one variable they must contend with during the supplier selection decision process. Indeed, studies have identified time pressure as an important determinant of both consumer behavior (Xu-Priour et al., 2012) and supplier selection decision (Garrido-Samaniego \& Gutiérrez-Cillán, 2004). Defined as the degree to which organizational buying decision-makers feel hurried or under pressure to make a purchase decision relatively quickly (Garrido-Samaniego \& Gutiérrez-Cillán, 2004), it is expected that public sector organisations, considering the limited life-cycle within which they need to deliver public-approved goods and services if they have to ensure their survival, will feel pressured by the exigencies of time to choose suppliers who can meet expectations on time and on budget.

However, given that decision makers in polychronic cultures have been shown to disregard or play-down the importance of planning and time co-coordination relative to set goals (because of their general perception of time as being an intangible resource that can neither be properly controlled nor planned) (Capdeferro et al., 2014; Hall, 1983; Lindquist \& Kaufman-Scarborough, 2007; Van Everdingen \& Waarts, 2003), we reason that public sector decision makers in Nigeria will not be perturbed by situations of time pressure during important supplier selection decisions. Polychronic-minded decisions makers are most likely to use avoidance strategies (for 
example, the excuse of 'consulting widely with important stakeholders') to needlessly delay or circumvent the process. This proclivity is aptly captured by the 'African Time' syndrome which generally describe Africans' poor time management and poor planning attitudes. It is not uncommon, for instance, to read reports of time-bound supply contracts legally entered, but never fully implemented. It is also not uncommon to find incomplete and abandoned 'phase 1' projects, even as the government is making plans for the 'phase 2' which may also never see the light of day. We posit, therefore, that rather than harness and concentrate effort at ensuring that the suppliers selected for government jobs are those who can deliver value-for-money within agreed time block, decision makers are most likely to be laid-back in their approach, taking all the time they need to negotiate and ensure a favourable deal for themselves and their associates. In view of the foregoing discussion, argue that time pressure perception will be inversely related to public sector supplier selection decisions in Nigeria, hence the following hypothesis:

\section{$\boldsymbol{H}_{1}$ : Time pressure perception causally determine supplier selection decisions in the Nigerian public sector.}

The question about the appropriate measures of public sector performance is still being debated in the relevant literature (Cho \& Poister, 2014; Pestieau, 2009). This is because, unlike private for-profit firms which may target a straight-forward objective of share holders' wealth or profit maximization, public sector firms are known to pursue multi-dimensional (and sometime conflicting) objectives during public supply jobs (Akenroye, 2013; Boyne \& Gould-Williams, 2003). Based on the 'performance approach' of agency theory suggested by Pestieau (2009), this study conceptualizes performance in terms of the extent to which organizations or organizational actors (i.e., the 'agents') achieve the goals and objectives assigned to them by the government/state or 'the people' (i.e., the 'principal'). This approach enhances the assessment of public sector performance against set benchmarks or public expectations (Pestieau, 2009; Propper \& Wilson, 2003). For every public supply decision made, for example, the intended objective may range from the completion of projects within budgeted resources (time, money, personnel), the development of small and medium enterprise (SME) capacity, the empowerment of indigenous contractors (and the encouragement of 'Local Content'), to the compensation of political sponsors. In this sense, performance is the result of an internal self-assessment or evaluation against benchmarks or standards set by a principal (Pestieau, 2009). Hence the performance of organisations is as 'perceived' by the organisation's members (Cho \& Poister, 2014).

For all decision makers, conditions of time pressure may create worrisome circumstances which may interfere with attention to details, thus affecting performance. Reported findings from the time pressure-performance literature generally indicate mixed results, ranging from positive to negative relationships, depending on a variety of factors such as the value placed on time, the source of pressure, and the psychological (cognitive) status of the decision-maker (Chong et al., 2011; Gross, 1994; Lin \& Wu, 2005; Xu-Priour et al., 2012). For the monochrons who are associated with a high value for time, for example, situations of time pressure make them more focused on the task at hand, more alert and creative at solving problems, and more challenged to accomplish task (Bluedorn et al., 1992; Lindquist \&Kaufman-Scarborough, 2007). These predispositions will lead to higher reward, productivity and performance (Arndt et al., 2006; Chong et al., 2011; Evans, Handley, \& Bacon, 2009). Polychrons, on the other hand, attach minimal to zero value to time. Rather than being spurred and challenged to prove self and achieve more during time-pressured situations, they would go into risk-avoidance mode by switching/moving to other tasks, deferring/delaying decision, being passive, welcoming distractions and interruption by taking on more responsibilities or engaging in hitherto unscheduled activities, and generally willing to change/abandon plans to please others (Benabou, 1999; Bluedorn et al., 1999; Hall, 1983; KaufmanScarborough \& Lindquist, 1999).

Given that polychronic cultures attach trivial value to time, and they are less likely to be unsettled by it, we expect that time pressure will undermine performance in Nigerian firms. This is because in the Nigerian public sector, decision makers do not feel the need to complete a project in a hurry. Even when they are time-pressured to deliver, they are more likely to appeal to their socio-ethnic and political connections (for the mitigation of any penalty that may arise from their non-performance) than focusing efforts to achieve desired results (Essien et al., 2018). In fact, there are numerous cases where important time-bound public work projects were commissioned, and huge mobilization fees paid to contractors, but such projects were either abandoned or never fully executed to specification (Achua, 2011; Osisioma, 2001). This means that rather than motivating decision makers to perform better (by making them more focused and goal-oriented), time pressure situations may lead to the activation of risk-avoidance and accountability-evading strategies with detrimental effect on performance. These arguments lead to the following hypothesis:

$\boldsymbol{H}_{2}$ : Time pressure perception is negatively and significantly associated with public sector performance in Nigeria. 


\subsection{Social Ties}

Social ties or interpersonal relationships is one important integral element of polychronic cultures that could explain both individual and group (organizational) behavior (Hall, 1983; Mohammed \& Nadkarni, 2014). Conceptualized as those informal self-motivated bonds and friendships cultivated and nurtured by organisational actors with both internal and external stakeholders for mutual benefits (Gonzalez, Claro, \& Palmatier, 2014; Peng \& Luo, 2000), social ties refer to those multiplex social connections which organizational actors often leverage on to influence organizational outcomes (Bowler, Dahlstrom, Seevers, \& Skinner, 2011; Gonzalez et al., 2014; Karahanna \& Preston, 2013)

As noted earlier, the supplier selection stage is a very important decision phase in the public procurement process, not least because several competing interests must be accommodated whilst still hoping to achieve set goals. These competing interests and goals may become sources of stress and concern for the decision makers who needs to be seen as competent and 'capable of delivering'. For the polychronic-minded manager, one option available to them to dissipate the stress and reduce the tension on themselves is to informally consult widely with 'important stakeholders' - business associates, close friends, family members, political allies, co-workers, government agents, and even the prospective suppliers. In other words, rather than face the decision challenge at hand alone, polychronic decision-makers are most likely to share the risk and benefit resulting from such decisions by negotiating an agreeable term in favour of themselves and their network of friends (Bluedorn et al., 1999; Xu-Priour et al., 2014). This makes some sense because it fits into the avoidance strategy often associated with polychronic people (Arndt et al., 2006; Bluedorn et al., 1999; Kaufman-Scarborough \& Lindquist, 1999). Moreover, it has been shown that decision makers leverage on their network of political connections to mitigate hostility from the business environment (Essien et al., 2018; Peng \& Luo, 2000). Based on the foregoing reasoning, we hypothesise that:

\section{$\boldsymbol{H}_{3}$ : Social ties will be Significantly Associated with Supplier Selection Decisions.}

Through their network of friends and personal connections with both government officials (i.e., politicians, law enforcement agents, important bureaucrats, regulatory authorities, etc.) and business associates (who could also be their tribal or religious leaders, old school mates, suppliers, or family relations), decision makers obtain leverage (or social capital) that may enhance their performance (Karahanna \& Preston, 2013; Kwon \& Adler, 2014; Peng \& Luo, 2000; Sheng et al., 2011). As an information exchange mechanism, social ties have been shown to provide 'insider' information not readily available in the open market for use by connected network members (Granovetter, 1983; Karahanna \& Preston, 2013; Kwon \& Adler, 2014). For the risk-averse decision maker, we suspect that rather than undertake a time-bound high-value task where failure may result in personal and corporate losses, they may delay their decisions as long as possible to either renegotiate terms or seek advice or more information. Thus, their social informal connections may provide them the social capital to enhance their co-ordination and mutually benefiting exchange activities.

In the Nigerian public sector, CEOs sometimes have to rely on their level of personal relationship (connection) with key members of authorizing bodies such as legislators and political party chieftains to get projects and budgets approved. Moreover, it is highly probable that appointment or recommendation for appointment to CEO and other important decision-making roles in public sector firms is largely based on ones' level of connection with key stakeholders in the system (Achua, 2011). Therefore, it is not out of place to think that decision makers will always use their connection as leverage to ensure a favourable outcome for themselves and their sponsors. Furthermore, given that public sector performance is assessed/evaluated mainly on qualitative/subjective criteria (Cho \& Poister, 2014; Pestieau, 2009), it is not out of place to think that performance appraisal officers who have being 'carried along' by the organization will neither award satisfactory performance scores to such organizations nor overlook incidences of sub-optimal performance by these organizations. Even in cases where non-performance may result in criminal liability (for example, where public managers connive with contractors and politicians to abandon work on important public projects after collecting huge mobilization fees), it is common knowledge that culprits often shield themselves from prosecution by appealing to their network of 'powerful connections' who may have directly or indirectly benefitted from their activities. Indeed, it is not uncommon to find public CEOs and contractors being rewarded on account of their social ties, despite their track record of incompetence and poor performance (Oguonu, 2007; Osisioma, 2001).

Therefore, consistent with the findings of some previous studies (e.g.,Essien, 2018; Gonzalez et al., 2014; Peng \& Luo, 2000), we argue that public sector decision makers' use of, and reliance on, their network of social connections will be strongly associated with their relevance/stewardship assessment scores (whether for good or otherwise). This argument is further reinforced by the 'Nigerian Factor'(Osisioma, 2001) and the 
'Man-Know-Man Factor' (Essien \& Etuk, 2012) whereby decision makers' relevance and survival in the public sector is a function of their clientelistic and prepredalistic relationships. To test this claim, we advance the following hypothesis:

\section{$\boldsymbol{H}_{4}$ : Social ties are significantly associated with perceived performance in the Nigerian public sector.}

\subsection{Supplier Selection Decisions}

An organizations' decision to choose one supplier rather than the other may have serious implications for its ability to attain set goals. As indicated earlier, the goals pursued by public organizations during procurement activities are diverse and multifaceted. This implies that for a firm to be seen as performing satisfactorily, it must, at the least, engage contractors who understand the modus operandi of public supply jobs, and are also willing to accommodate the competing interest that often characterize the process. The choice of the 'right' supplier may lead to overall satisfaction for the stakeholders and a satisfactory assessment/performance appraisal. However, the choice of the 'wrong' supplier may lead to undesirable outcomes, including a dissatisfied principal, project abandonment or poor quality of work execution. Therefore, given that the strategic decisions made by organizations critically affects their health and survival (Eisenhardt \& Zbaracki, 1992), we posit that the supplier selection decisions made by public sector organisations shall reflect on their performance.

$\boldsymbol{H}_{5}$ : Supplier selection decisions will be significantly associated with perceived performance in public sector organizations.

\section{Research Methodology}

\subsection{Sampling and Data Collection}

A purposeful sampling strategy was employed to select the organizations included in this study. We used the Schedule to the Nigeria Fiscal Responsibility Act of 2007 (as amended) and relevant Nigerian Government Gazettes as the sampling frame that guided our selection. In all 40 public organizations that were identified as pro-business-but-not-for-profit were selected. These firms were all created by Acts of Parliament.

Structured questionnaires were developed after a thorough literature review of the constructs domain and then administered to selected respondents in the identified firms. Prior to the questionnaire administration, it was checked for content validity by the first author's PhD supervisors after which it was pretested on ten Nigerian senior public servants (including 3 senior academics). For the main survey, we administered hard copies of the questionnaire to i5 individuals in each of the 40 organizations sampled. These individuals were identified by their explicit responsibilities/roles in their respective organizations as either heads of department/unit or senior staff/principal officers. We used a multi-informant approach so as to obtain a representative aggregate cross-section of opinions on the phenomena being assessed. After checking for non-valid questionnaires and completeness of responses, we retained 342 usable questionnaires out of the 600 distributed (representing a response rate of 57\%). It is pertinent to note that we did not find any significant differences between the organizations that returned their survey and those that did not in terms of their sub-sector, size or organizational characteristics.

We realize that the use of a single questionnaire/source in cross-sectional studies to collect data on both the dependent and independent variables may result in common method bias (Podsakoff, MacKenzie, \& Podsakoff, 2012). To check for the existence of common method bias, we conducted the Harman one-factor test. The exploratory factor outcome based on this test shows that no one factor accounted for a great proportion of the observed variance. Therefore, the chances for our results being biased by common method variance is very small and insignificant.

\subsection{Operationalization of Constructs}

We adapted and used the scales that were developed and tested in previous studies. To measure time pressure perception, we adapted the scales used by Garrido-Samaniego \& Gutiérrez-Cillán (2004) and Rizkalla (1989). The scale comprise four items that captures the respondents' perception of the extent to which decision makers in their organization 'feels the need to consider all options when faced with important decisions'; 'feel stressed and disorientated when they have to make a decision quickly'; 'behave like there is never enough time to follow all due process requirements'; and 'time is always sufficient for all competing interests to be considered during decision situations'. To measure social ties, we relied on the scales used by Peng \& Luo (2000) and Li, Poppo, \& Zhou (2008). The scale is made up of five item that captures the extent to which respondents feel that decision makers in their organizations have good personal connections with influential stakeholder including elected/appointed party officials, contractors, government regulatory agents, law enforcement agents, and ethic/religious leaders. For supplier selection decision, we adapted four measures from the studies by Ehrgott, 
Reimann, Kaufmann, \& Carter (2011) and Kannan \& Tan (2002). The scales capture the degree of importance attached to supplier selection criteria related to quality requirements, cost savings requirements, deliverability requirements, and ethicality requirements.

Table 1. Inter-construct correlation coefficients

\begin{tabular}{llllll}
\hline Constructs & 1 & 2 & 3 & 4 & 5 \\
1. Time pressure & 0.83 & & & & \\
2. Social ties & 0.09 & 0,78 & & & \\
3. Sup. Sel. Dec. & -0.11 & 0.47 & 0.68 & 0.71 & 0.89 \\
4. Performance & -0.36 & 0.08 & 0.11 & 0.28 & \\
5. Funding & 0.02 & 0.13 & -0.04 & & \\
\hline
\end{tabular}

Note: The values on the diagonal are the square roots of AVE.

Finally, we adopted the scale for perceived performance in the public sector from Cho \& Poister (2014). Our scale comprises four items that captures respondents' perception of the degree to which their organization/decision makers 'carry out all the activities planned for a budget period'; 'adequately completes all planned projects on schedule'; 'deliver affordable quality services to the public as contained in the public service contract'; and 'are confident of receiving positive feedback on performance from the service users'. In addition to the constructs specified in our proposed model, we included 'requisite funding' as a control variable on both supplier selection decision and performance. Extant studies suggest the availability (or unavailability) of sufficient budgetary provisions impact on public organizations' choice outcomes as well as their ability to accomplish set goals (Lindskog et al., 2010; Roman, 2013). Requisite funding was measured by three items whereby respondents were asked to rate the degree to which their organization 'depend heavily on government for funding'; 'can survive without government funding'; and 'asset purchase ability is seriously affected by government budgetary allocations'.

All the items were measured on a 5-point Likert scale anchored on 'strongly disagree' (1) to 'strongly agree' (5). The items' face validity was also examined as part of the questionnaire content validity check. This led to the adjustment of the wordings of some of the items. To investigate the constructs' unidimensionality, discriminant and convergent validity, we used confirmatory factor analysis (CFA) in Amos software, Version 18 (Table 1). The average variance extracted (AVE) for each of the sub-scale is greater than $50 \%$, indicating unidimensionality - a situation where items underlying a construct share a greater proportion of their variance with that construct than with other constructs in the instrument (Gerbing \& Anderson, 1988). The CFA result also shows that each item loaded highly and significantly on their respective construct, thus indicating convergent validity. To assess discriminant validity, we followed the guidelines suggested by Fornell \& Larcker (1981). The square root of the AVE for each construct is higher than the inter-construct correlation value for that construct (see the diagonal values on Table 1), thus fulfilling the condition for discriminant validity.

On the whole, the CFA of our measurement model suggest that the measurement parameters are within conventional limits: chi square was $574.068(\rho<0.001, d f=370)$, goodness of fit index $(\mathrm{GFI}=0.92)$, comparative fit index (CFI = 0.98), incremental fit index (IFI $=0.97)$, Tucker Lewis index (TLI = 0.98), and root mean square error of approximation (RMSEA $=0.061$ ). These fit statistics are indicators of a good and acceptable measurement model (Fornell \& Larcker, 1981; Gerbing \& Anderson, 1988).

\section{Results of Data Analysis}

\subsection{Descriptive Statistics}

Out of the 342 respondents who were included in the analysis, 211 (61.7\%) were male and 131 (38.3\%) were female. On average, the respondents are 40.2 years old $(S D=10.95)$, and they have worked in the public sector for 16.7 years $(\mathrm{SD}=7.61)$. With respect to the public sub-sectors the participants are employed, $106(31 \%)$ respondents are employed in educational institutions, 97 (28.4\%) are employed in the public health sector, 50 employees (14.6\%) belong to the manufacturing sub-sector, $25(7.3 \%)$ of the participants are employed in the financial services sector, and the remainder (64 participants or $18.7 \%$ of the respondents) belong to 'other' sub-sectors including telecommunication and media. Regarding the highest educational attainment of the various participants, 51 respondents (14.9\%) studied up to Diploma Level, 198 (57.9\%) hold a first degree or equivalent certificate, 78 participants $(22.8 \%)$ have a master's degree or equivalent, and 15 participants (or $4.4 \%$ of respondents) hold a $\mathrm{PhD}$ degree. 


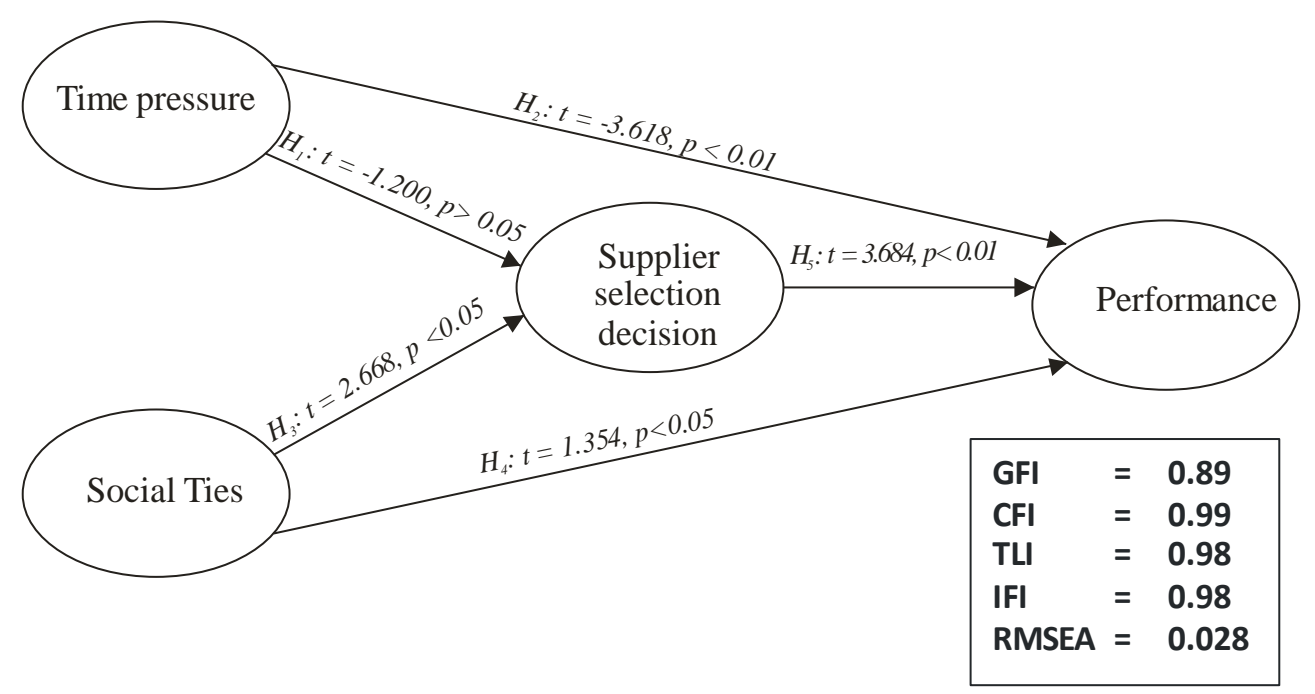

Figure 2. Structural Model with Path Estimates

\subsection{Hypotheses Testing}

To test our hypothesized relationships simultaneously, we used structural equation modelling (SEM) techniques by applying the maximum likelihood estimation (MLE) method in AMOS software (version 18). While examining the data-to-model fit statistics produced by the first model run, we found that the integrity of the model could be improved by allowing some items on the respective independent variables to co-vary. These modifications significantly improved the model fit indices: Chi-square was $844.365(d f=464, \rho=0.003)$; GFI $=$ 0.89; $\mathrm{CFI}=0.99$; TLI $=0.98$; RMSEA $=0.028$; and IFI $=0.98$. After satisfying ourselves that the structural model was acceptable, because all the fit indices were within recommended cut-off points (Byme, 2016), we went ahead to examine the path estimates of the hypothesized relationships proposed (Figure 2).

Our data did not support $\mathbf{H}_{\mathbf{1}}$ because the time pressure perception of decision makers in the public sector was not found to significantly influence their supplier selection behavior $(t=-1.200, p>0.05)$. However, we found supportive evidence for the negative influence of time pressure and performance in the public sector $\left(\mathbf{H}_{2}: t=\right.$ -3.618. $p<0.01)$. On the other hand, we found that the social ties cultivated and nurtured by organizational decision makers positively influenced their supplier selection choices $\left(\mathbf{H}_{3}: t=2.668, p<0.05\right)$, but these ties have no significant impact on their performance $\left(\mathbf{H}_{4}: t=1.354, p>0.05\right)$. Therefore, although our data did not confirm $\mathbf{H}_{\mathbf{4}}$, it provided empirical support for $\mathbf{H}_{3}$. Consistent with our expectations, our data indicates that the supplier selection decisions made by Nigerian public sector firms impact on their performance $(t=3.684, p<$ 0.01), thus supporting $\mathbf{H}_{5}$.

Though not hypothesized, our result seemed to suggest that supplier selection decisions mediates the relationship between social ties and performance, so we decided to probe further using the three-step approach suggested by Baron \& Kenny (1986). First, we established that social ties is significantly related to supplier selection decision $(P<0.05)$. Second, we specified and estimated a new model of the direct relationship between the independent variables (i.e., time pressure and social ties) and performance as the sole dependent variable (thus, excluding supplier selection decisions). Without the presence of supplier selection decisions, we found that social ties was significantly related to performance $(p<0.05)$, thus satisfying the second condition for mediation (Baron \& Kenny, 1986). Third, the re-introduction of supplier selection decisions path way resulted in a significant relationship between supplier selection decisions and performance but a non-significant relationship between social ties and performance, thus indicating the mediatory role of supplier selection decision in the relationship between social ties and performance in the public sector.

\section{Discussion - Conclusions and Implications}

Despite acknowledging that time pressure perception and social ties may be theoretically linked in explaining organizational outcomes, as well as acknowledging that their effects may vary depending on context, only a few studies in the literature have examined the possible influence of time pressure perception and social ties on the supplier selection decisions and the performance of public sector firms in a typical polychronic cultural setting like Nigeria. The public sector is potentially the largest goods and services consumer in any economy in terms of sales volume and Dollar turnover (Lindskog et al., 2010; Wright, 2004). Our study contributes to the literature by 
broadening our understanding of the relative importance of these variables in explaining supplier selection decisions, and the extent to which resultant decisions may impact performance in public sector firms. Moreover, our findings and conclusions may have useful implications for both theory and practice.

Our result indicates that time pressure is inversely and significantly related to performance. This suggests that rather than being more focused and goal-oriented at tackling the task at hand when faced with deadlines, Nigerian public sector decision makers are more likely to be relaxed, favouring the use of avoidance strategies to gain (or waste) more time, and these attitudes have detrimental effects on performance. Therefore, we conclude that Nigerian public employees' time management culture is inimical to productivity and performance in the public sector. This conclusion is consistent with previous studies that found that managers who perceive time pressure as a hindrance (and also try to avoid it) will perform less than those who perceive it as a challenge that needs to be embraced and surmounted (Chong et al., 2011). Given that Nigerians are generally polychronic, it will appear that time-pressured situations will always lead to sub-optimal performance because of their disregard for the economic value of time. Detailed planning and coordination of activities can significantly mitigate the stress brought about by time-pressured situations, thus improving performance (Chong et al., 2011; Roskes, Elliot, Nijstad, \& De Dreu, 2013). Therefore, just like personnel, materials and money, time must be viewed as a scarce tangible resource that must be professionally managed if public sector firms are to be seen as performing satisfactorily. For instance, budgeted resources should be released to contractors on time to avoid rushed procurements that may result in poor quality output or abandoned projects. Similarly, government firms should imbibe the culture of scheduling and completing projects sequentially, rather than the practice of moving back and forth between projects within a budgeted time block (for e.g., commencing the second phase of a project even when the first phase is yet to be completed). Such simultaneity may suggest lack of orderliness and insufficiency of time, and this may negatively impact performance.

Contrary to our expectations however, the relationship between time pressure and supplier selection decision was not significant. The negative and non-significant relationship between time pressure and supplier selection decision may imply that although Nigerian public sector decision makers manage time-bound decision activities by applying delay and avoidance strategies (including the postponement of decisions where possible), this attitude is not such a critical determinant of who gets selected as contractor. Therefore, this study concludes that public sector decision makers in Nigeria are not perturbed by time-pressured situations to the extent that they can set aside the important policy requirements for selecting contractors. In fact, it is very possible that whether or not decision makers defer/avoid a decision process (for the reason of 'consulting widely' with stakeholders or accommodating personal interest), they may still be constrained to select a particular supplier because of the technical nature of the supply job at hand.

For the foreign investor who may not be very familiar with the business culture of Nigerian public firms, it is very important to meet (and surpass) the minimum technical requirements for advertised public works, if they must stand a chance of being selected. During time-bound procurement processes, prospective suppliers may experience frequent delays and postponements to scheduled meetings, they may be summoned to attend impromptu and unscheduled meetings, they may be requested to engage in off-the-record negotiations, and they may find themselves engaged in back-and-forth negotiations with seemingly no end in sight. Investors should not be put-off because, though these behaviors are typical of the Nigerian public procurement system, they do not critically determine who is awarded the final supply contract. Therefore, prospective suppliers and contractors should concentrate on improving the technical superiority of their offers/bids to enhance their chances of success.

Our study found a positive and significant relationship between supplier selection decisions and perceived performance. This result confirms our hypothesis and supports our argument that the supplier selection choices made by public sector organizations may impact their performance prospects; choosing the right and most qualified contractor will increase a firm's chances of achieving its decision objectives, thus satisfying its stakeholders. This result is also consistent with previous studies that found that the decision choices made by organization critically impact on the health and survival of that organization in terms of the resources committed and the precedent set (Eisenhardt \& Zbaracki, 1992; Kannan \& Tan, 2002).Therefore, public sector firms will improve their performance prospect and goal-attainment capabilities by contracting suppliers who have the track records for delivering within agreed timelines and terms. As a matter of policy therefore, public sector organizations should only engage as contractors, individuals and entities who have earned their reputation by their previous experience or only those who have the capacity to deliver on a given job. By so doing, the firm will continue to attract positive performance ratings, whilst still meeting the multiple goals often associated with public sector procurement. 
Though not hypothesized, our result also indicates that supplier selection decisions fully mediate the relationship between social ties and performance in public sector organizations. This is demonstrated by the non-significant path way estimate between social ties and performance, and the significant indirect path way estimates going from social ties to performance through supplier selection decisions (Figure 2). The significantly positive influence that social ties have on supplier selection decision may suggest that the wider and deeper the interpersonal network of informal relationship maintained by organizational actors, the greater their chances of selecting the types of suppliers or contractors that will yield the kind of outcomes desirable to stakeholders. On the other hand, the non-significant relationship between social ties and performance may imply that the width and depth of the personal connections maintained by decision makers in public sector organizations does not necessarily translate to higher performance; these connections will only be meaningful to performance if they lead to the selection of the 'right' suppliers. This conclusion is largely consistent with previous studies that found that social ties are important determinants of organizational behavior (Essien et al., 2018), and they may influence organizational outcomes indirectly via appointments to decision making roles and level of resource allocation (Li et al., 2008; Peng \& Luo, 2000; Sheng et al., 2011).

Public sector contracts could be very lucrative and competitive, and the fact that a contractor has been short-listed is not a guarantee that they may get the job. The significant positive relationship between social ties and supplier selection decisions implies that suppliers that spare no effort at associating and socializing with important stakeholders in the procurement system (ministerial tender board members, permanent secretaries, heads of procurement units, politicians, senior public servants, legislators, etc.) stand a better chance of being awarded public sector supply jobs. By developing close ties with the information gatekeepers in the procurement system, for example, potential suppliers may become privy to important 'insider information' that may enhance the acceptability of their bids. It is also possible that some requirements for the supply job at hand may be waived for a contractor because of their personal relationship with an important approving officer or agent. In fact, it has been observed that contractors may have to rely on their political connections to secure a contract (Achua, 2011), and Ministers of contracting entities in Nigeria have the discretionary powers to overlook certain requirements of the public procurement regulations in favour of a bidding firm (Nwapi, 2015).

Therefore, although the proposed relationship between social ties and performance was not verified by our results, we can cautiously conclude that (based on the positive indirect link between social ties and performance) it is not the level of stakeholders' connections per se that leads to positive performance outcomes in public sector organizations, rather the extent to which such connections enhance the selection of suitable suppliers is more critical to performance. In addition to maintaining a wide network of influential friends who can be relied on when the need arises, it is very important for public sector decision makers to demonstrate competence and knowledge when selecting contractors. In the same vein, prospective suppliers should project their technical competence and capabilities, whilst still ensuring that they maintain a healthy mutually-benefitting relationship with important stakeholders in the procurement system. This means that competence and expertise for delivering to specification is far more critical to the positive performance of public firm than, say, social ties alone.

\section{Limitations and Suggestions for Further Research.}

This study contains some limitations that needs to be highlighted here. For the purpose of confirming the conclusions arrived at in this study, as well as supporting or refuting the results of this study, further research is needed. This study only examined the influence of time pressure perception and social ties on both supplier selection decisions and performance without considering some of the important variables that may mediate/moderate this relationship. Future research may incorporate such variables as ethical work climate perception, personal value orientation of decision makers, and the prevalence of political party pressure, etc., into their model. This is because some studies have shown that these variables play important roles during public sector supplier selection (Essien, 2018). Secondly, the supplier selection decision phase is only a single stage in the public procurement process (Lindskog et al., 2010). It is possible that the independent variables examined in this study may have different effects on the other decision stages. Therefore, researcher may consider examining the influence of these variables on either the post- or pre-supplier decision selection stages with a view to comparing/generalizing our results. Furthermore, future researchers may consider more standardised performance measures such as budget performances score cards or independent auditors' evaluation as proxy for public sector performance, instead of perceptual measures which have been found to be highly subjective.

Finally, the lack of a standardized instrument for measuring time pressure is an important limitation in our study. Various studies apply a variety of approaches to examine and measure the effect of time pressure on various outcomes, thus leading to different findings. For instance, while Chong et al.(2011) measured time pressure using a 5-item scale adapted from the instrument for stress oriented task (ISOTA), Garrido-Samaniego \& 
Gutiérrez-Cillán(2004) used a 5-point Likert scale specifically developed and validated for measuring time pressure in business-to-business marketing context. Therefore, we suggest that caution be applied while interpreting our results because more empirical studies are needed in polychronic contexts to verify our claims.

\section{References}

Achua, J. K. (2011). Anti-corruption in public procurement in Nigeria: Challenges and competency strategies. Journal of Public Procurement, 11(3), 323-333. https://doi.org/10.1108/JOPP-11-03-2011-B002

Akenroye, T. O. (2013). An appraisal of the use of social criteria in public procurement in Nigeria. Journal of Public Procurement, 13(03), 364-397. https://doi.org/10.1108/JOPP-13-03-2013-B005

Arndt, A., Arnold, T. J., \& Landry, T. D. (2006). The effects of polychronic-orientation upon retail employee satisfaction and turnover. Journal of Retailing, 82(4), 319-330. https://doi.org/10.1016/j.jretai.2006.08.005

Ayoun, B., \& Moreo, P. (2009). Impact of Time Orientation on the Strategic Behavior of Thai and American Hotel Managers. Journal of Hospitality Marketing \& Management, 18(7), 676-691. https://doi.org/10.1080/19368620903170224

Baron, R. M., \& Kenny, D. A. (1986). The moderator-mediator variable distinction in social psychological research: Conceptual, strategic, and statistical considerations. Journal of Personality and Social Psychology, 51(6), 1173. https://doi.org/10.1037/0022-3514.51.6.1173

Benabou, C. (1999). Polychronicity and temporal dimensions of work in learning organizations. Journal of Managerial Psychology, 14(3/4), 257-270. https://doi.org/10.1108/02683949910263792

Bluedorn, A. C., Kalliath, T. J., Strube, M. J., \& Martin, G. D. (1999). Polychronicity and the Inventory of Polychronic Values (IPV): The development of an instrument to measure a fundamental dimension of organizational culture. Journal of Managerial Psychology, 14(3/4), 205-231. https://doi.org/10.1108/02683949910263747

Bluedorn, A. C., Kaufman, C. F., \& Lane, P. M. (1992). How many things do you like to do at once? An introduction to monochronic and polychronic time. Academy of Management Perspectives, 6(4), 17-26. https://doi.org/10.5465/ame.1992.4274453

Bowler, W. M., Dahlstrom, R., Seevers, M. T., \& Skinner, S. J. (2011). The ties that buy: the role of interfirm social contagion across customer accounts. Journal of Personal Selling \& Sales Management, 31(1), 7-20. https://doi.org/10.2753/PSS0885-3134310101

Boyne, G., \& Gould-Williams, J. (2003). Planning and Performance in Public Organizations an empirical analysis. Public Management Review, 5(1), 115-132. https://doi.org/10.1080/146166702200002889

Byme, B. M. (2016). Structural equation modeling with Amos: Basic concepts, applications and programming (3rd ed.). New York: Routledge.

Capdeferro, N., Romero, M., \& Barberà, E. (2014). Polychronicity: review of the literature and a new configuration for the study of this hidden dimension of online learning. Distance Education, 35(3), 294-310. https://doi.org/10.1080/01587919.2015.955249

Chen, C., Xu, H., \& Zheng, J. (2015). The Relationship Between Economic Value of Time and Feelings of Time Pressure. Social Behavior and Personality: An International Journal, 43(8), 1395-1407. https://doi.org/10.2224/sbp.2015.43.8.1395

Cho, Y. J., \& Poister, T. H. (2014). Managerial practices, trust in leadership, and performance: Case of the Georgia department of transportation. Public Personnel Management, 43(2), 179-196. https://doi.org/10.1177/0091026014523136

Chong, D. S. F., Eerde, W. V., Chai, K. H., \& Rutte, C. G. (2011). A Double-Edged Sword: The Effects of Challenge and Hindrance Time Pressure on New Product Development Teams. IEEE Transactions on Engineering Management, 58(1), 71-86. https://doi.org/10.1109/TEM.2010.2048914

Ehrgott, M., Reimann, F., Kaufmann, L., \& Carter, C. R. (2011). Social sustainability in selecting emerging economy suppliers. Journal of Business Ethics, 98(1), 99-119. https://doi.org/10.1007/s10551-010-0537-7

Eisenhardt, K. M., \& Zbaracki, M. J. (1992). Strategic decision making. Strategic Management Journal, 13(S2), 17-37. https://doi.org/10.1002/smj.4250130904

Essien, E. E. (2018). The influence of ethical work climates on public sector supplier selection decisions. British Journal of Marketing Studies, 6(5), 62-83. 
Essien, E. E., Konstantopoulou, A., Konstopoulos, I., \& Lodorfos, G. (2018). The influence of business and political ties on supplier selection decisions: the case of the Nigerian public sector. International Journal of Foresight and Innovation Policy, 13(1-2), 71-87. https://doi.org/10.1504/IJFIP.2018.095859

Essien, E. E., \& Etuk, E. J. (2012). Government Policy Requirements and Personal Considerations as Determinants of Organizational Buying Behavior. European Journal of Business and Management, 4(6), 131-137.

Evans, J. S. B., Handley, S. J., \& Bacon, A. M. (2009). Reasoning under time pressure: A study of causal conditional inference. Experimental Psychology, 56(2), 77-83. https://doi.org/10.1027/1618-3169.56.2.77

Faccio, M. (2010). Differences between politically connected and nonconnected firms: A cross-country analysis. Financial Management, 39(3), 905-928. https://doi.org/10.1111/j.1755-053X.2010.01099.x

Fornell, C., \& Larcker, D. F. (1981). Evaluating structural equation models with unobservable variables and measurement error. Journal of Marketing Research, 39-50. https://doi.org/10.1177/002224378101800104

García, J. A., \& Ruiz, B. (2015). Exploring the Role of Time Perspective in Leisure Choices: What About the Balanced Time Perspective? Journal of Leisure Research, 47(5), 515-537. https://doi.org/10.18666/jlr-2015-v47-i5-5876

Gerbing, D. W., \& Anderson, J. C. (1988). An updated paradigm for scale development incorporating unidimensionality and its assessment. Journal of Marketing Research, 186-192. https://doi.org/10.1177/002224378802500207

Gonzalez, G. R., Claro, D. P., \& Palmatier, R. W. (2014). Synergistic effects of relationship managers' social networks on sales performance. Journal of Marketing, 78(1), 76-94. https://doi.org/10.1509/jm.11.0431

Granovetter, M. (1983). The strength of weak ties: A network theory revisited. Sociological Theory, 1, 201-233. https://doi.org/10.2307/202051

Gross, B. L. (1994). Consumer responses to time pressure: A qualitative study with homeowners in foreclosure. Advances in Consumer Research, 21, 120-125.

Hadjikhani, A., \& LaPlaca, P. (2013). Development of B2B marketing theory. Industrial Marketing Management, 42(3), 294-305. https://doi.org/10.1016/j.indmarman.2013.03.011

Hall, E. T. (1959). The silent language. New York, NY: Anchor Books.

Hall, E. T. (1983). The dance of life: The other dimension of time. New York, NY: Doubleday.

Ho, T. H., Lim, N., \& Camerer, C. F. (2006). How "psychological" should economic and marketing models be? Journal of Marketing Research, 43(3), 341-344. https://doi.org/10.1509/jmkr.43.3.341

Iyer, G. R., Xiao, S. H., Sharma, A., \& Nicholson, M. (2015). Behavioral issues in price setting in business-to-business marketing: A framework for analysis. Industrial Marketing Management, 47, 6-16. https://doi.org/10.1016/j.indmarman.2015.02.001

Garrido-Samaniego, M. J., \& Gutiérrez-Cillán, J. (2004). Determinants of influence and participation in the buying center. An analysis of Spanish industrial companies. Journal of Business \& Industrial Marketing, 19(5), 320-336. https://doi.org/10.1108/08858620410561051

Kannan, V. R., \& Tan, K. C. (2002). Supplier selection and assessment: Their impact on business performance. Journal of Supply Chain Management, 38(3), 11-21. https://doi.org/10.1111/j.1745-493X.2002.tb00139.x

Karahanna, E., \& Preston, D. S. (2013). The effect of social capital of the relationship between the CIO and top management team on firm performance. Journal of Management Information Systems, 30(1), 15-56. https://doi.org/10.2753/MIS0742-1222300101

Kaufman-Scarborough, C., \& Lindquist, J. D. (1999). Time management and polychronicity: Comparisons, contrasts, and insights for the workplace. Journal of Managerial Psychology, 14(3/4), 288-312. https://doi.org/10.1108/02683949910263819

Kotabe, M., \& Helsen, K. (2001). Global marketing management (2nd ed.). New York: Willey.

Kwon, S. W., \& Adler, P. S. (2014). Social capital: Maturation of a field of research. Academy of Management Review, 39(4), 412-422. https://doi.org/10.5465/amr.2014.0210

Lee, H., \& Sawyer, S. (2010). Conceptualizing time, space and computing for work and organizing. Time \& Society, 19(3), 293-317. https://doi.org/10.1177/0961463X10354429 
Li, J. J., Poppo, L., \& Zhou, K. Z. (2008). Do managerial ties in China always produce value? Competition, uncertainty, and domestic vs. foreign firms. Strategic Management Journal, 29(4), 383-400. https://doi.org/10.1002/smj.665

Lin, D. C. H., \& Wu, P. H. (2005). How to Deal With Conflicts? The Effect of Consumers' Subjective Time Pressure on Product Attitude Judgment and Choice, 7.

Lindquist, J. D., \& Kaufman-Scarborough, C. (2007). The Polychronic-Monochronic Tendency Model: PMTS scale development and validation. Time \& Society, 16(2-3), 253-285. https://doi.org/10.1177/0961463X07080270

Lindskog, H., Brege, S., \& Brehmer, P.-O. (2010). Corruption in public procurement and private sector purchasing. Journal of Organisational Transformation \& Social Change, 7(2), 167-188. https://doi.org/10.1386/jots.7.2.167_1

Malloy, D. C., \& Agarwal, J. (2010). Ethical climate in government and nonprofit sectors: Public policy implications for service delivery. Journal of Business Ethics, 94(1), 3-21. https://doi.org/10.1007/s10551-008-9777-1

Mohammed, S., \& Nadkarni, S. (2014). Are we all on the same temporal page? The moderating effects of temporal team cognition on the polychronicity diversity-team performance relationship. Journal of Applied Psychology, 99(3), 404-422. https://doi.org/10.1037/a0035640

Nonis, S. A., Teng, J. K., \& Ford, C. W. (2005). A cross-cultural investigation of time management practices and job outcomes. International Journal of Intercultural Relations, 29(4), 409-428. https://doi.org/10.1016/j.ijintrel.2005.05.002

Nwapi, C. (2015). Corruption vulnerabilities in local content policies in the extractive sector: An examination of the Nigerian Oil and Gas Industry Content Development Act, 2010. Resources Policy, 46, 92-96. https://doi.org/10.1016/j.resourpol.2015.09.001

Oguonu, C. N. (2007). Due process and procurement in the Nigerian public sector. African Renaissance, 4(1), 91-99.

Osisioma, B. C. (2001). Financial ethics: the issues of identifying and eliminating wasteful practices in the public sector. The Nigerian Journal of Banking and Finance, 4(1), 1-15.

Palmer, D. K., \& Schoorman, F. D. (1999). Unpackaging the multiple aspects of time in polychronicity. Journal of Managerial Psychology, 14(3/4), 323-345. https://doi.org/10.1108/02683949910263918

Peng, M. W., \& Luo, Y. (2000). Managerial ties and firm performance in a transition economy: The nature of a micro-macro link. Academy of Management Journal, 43(3), 486-501.

Pestieau, P. (2009). Assessing the performance of the public sector. Annals of Public and Cooperative Economics, 80(1), 133-161. https://doi.org/10.1111/j.1467-8292.2008.00380.x

Podsakoff, P. M., MacKenzie, S. B., \& Podsakoff, N. P. (2012). Sources of method bias in social science research and recommendations on how to control it. Annual Review of Psychology, 63, 539-569. https://doi.org/10.1146/annurev-psych-120710-100452

Propper, C., \& Wilson, D. (2003). The use and usefulness of performance measures in the public sector. Oxford Review of Economic Policy, 19(2), 250-267. https://doi.org/10.1093/oxrep/19.2.250

Rees-Caldwell, K., \& Pinnington, A. H. (2013). National culture differences in project management: Comparing British and Arab project managers' perceptions of different planning areas. International Journal of Project Management, 31(2), 212-227. https://doi.org/10.1016/j.ijproman.2012.04.003

Rizkalla, A. N. (1989). Sense of time urgency and consumer well-being: testing alternative causal models. ACR North American Advances.

Roman, A. V. (2013). The politics of bounded procurement: Purists, brokers and the politics-procurement dichotomy. Journal of Public Procurement, 13(4), 447-475. https://doi.org/10.1108/JOPP-13-04-2013-B002

Roskes, M., Elliot, A. J., Nijstad, B. A., \& De Dreu, C. K. (2013). Time pressure undermines performance more under avoidance than approach motivation. Personality and Social Psychology Bulletin, 39(6), 803-813. https://doi.org/10.1177/0146167213482984

Sheng, S., Zhou, K. Z., \& Li, J. J. (2011). The effects of business and political ties on firm performance: Evidence from China. Journal of Marketing, 75(1), 1-15. https://doi.org/10.1509/jm.75.1.1 
SURI, R., \& MONROE, K. B. (n.d.). The Effects of Time Constraints on Consumers' Judgments of Prios and Products. JOURNAL OF CONSUMER RESEARCH, 14.

Van Everdingen, Y. M., \& Waarts, E. (2003). The effect of national culture on the adoption of innovations. Marketing Letters, 14(3), 217-232. https://doi.org/10.1023/A:1027452919403

Wright, R. (2004). Business-to-business marketing: a step-by-step guide. Essex: Pearson Education.

Xu-Priour, D. L., Cliquet, G., \& Fu, G. (2012). The combined influence of time pressure and time orientation on consumers' multichannel choice: evidence from China. The International Review of Retail, Distribution and Consumer Research, 22(5), 529-546. https://doi.org/10.1080/09593969.2012.711256

Xu-Priour, D. L., Cliquet, G., \& Palmer, A. (2017). The Influence of Buyers' Time Orientation on Online Shopping Behavior: A Typology. International Journal of Electronic Commerce, 21(3), 299-333. https://doi.org/10.1080/10864415. 2016.1319206

Xu-Priour, D. L., Truong, Y., \& Klink, R. R. (2014). The effects of collectivism and polychronic time orientation on online social interaction and shopping behavior: A comparative study between China and France. Technological Forecasting and Social Change, 88, 265-275. https://doi.org/10.1016/j.techfore.2014.07.010

Zimbardo, P. G., \& Boyd, J. N. (2015). Putting time in perspective: A valid, reliable individual-differences metric. In Time perspective theory; review, research and application ( $\mathrm{pp}$. 17-55). Springer. https://doi.org/10.1007/978-3-319-07368-2_2

\section{Copyrights}

Copyright for this article is retained by the author(s), with first publication rights granted to the journal.

This is an open-access article distributed under the terms and conditions of the Creative Commons Attribution license (http://creativecommons.org/licenses/by/4.0/). 